\title{
OS ECOS DAS REVOLUÇÕES DE 1848 NO BRASIL FORMAS DE PENSAMENTO, LITERATURA POLÍTICA E TRANSFERÊNCIAS CULTURAIS
}

DEAECTO, Marisa Midori ${ }^{1}$

Todas as nossas revoluções foram, dir-se-ia, ondulações começadas em Paris. Joaquim Nabuco, Um Estadista no Império (1936, t. I, p. 72)

RESUMO: O presente artigo propõe um estudo sobre a recepção dos debates políticos ensejados durante as Revoluções de 1848, na Europa, a partir de suas matrizes francesas, entre literatos e figuras políticas atuantes no Brasil. A análise parte da leitura que os jornais cariocas fizeram da Revolução que eclode em Paris, em 23 de fevereiro de 1848, destronando o rei Luís Filipe. Para melhor dimensionar o comportamento da imprensa e de seus arautos nesse momento, propõe-se um quadro comparativo entre o parti pris político dos formadores da opinião pública frente à Revolução de 1830 e, depois, em 1848. Tal perspectiva nos permite observar, por meio de um estudo de caso, a saber, a recepção do libelo antidemocrático de François Guizot, o modus operandi da classe política na promoção da propaganda antirrevolucionária (em 1848), ao mesmo tempo que a imagem do jurista e ideólogo francês será reabilitada em uma chave oposta àquela apreendida em 1830. Ou seja, de paladino das liberdades constitucionais, o doutrinário francês se converte em opositor visceral do sufrágio universal e das lutas sociais, num só termo, do que ele classifica como "idolatria democrática".

PALAVRAS-CHAVE: Primavera dos Povos; Revolução Praieira; François Guizot; Democracia.

\section{LES ÉCHOS DES RÉVOLUTIONS DE 1848 AU BRÉSIL FORMES DE PENSÉE, LITTERATURE POLITIQUE ET TRANSFERTS CULTURELS}

\footnotetext{
${ }^{1}$ Profa. Livre Docente em História do Livro da Escola de Comunicações e Artes e do Programa de Pós-Graduação em História Econômica da Universidade de São Paulo. Pesquisadora do GrUPEBRAF (Instituto de Estudos Avançados-USP). O artigo compõe uma parte da pesquisa e do curso ministrado no IHMC-ENS, Paris, como professora-convidada do Labex-Transfers, em 2017, sob a supervisão de Frédéric Barbier.
} 


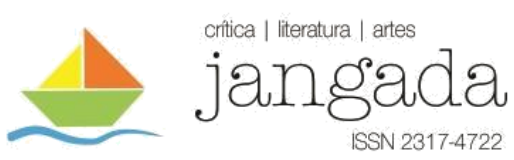

RÉSUMÉ : Cet article propose une étude de la réception des débats politiques entraînés lors des révolutions de 1848, en Europe, à partir de leurs matrices françaises, parmi des personnalités littéraires et politiques actives au Brésil. L'analyse se fonde sur la lecture que les journaux de Rio de Janeiro ont faite de la révolution éclatée à Paris, au 23 février 1848, détrônant le roi Louis Philippe. Afin de mieux mesurer le comportement de la presse et de ses hérauts à cette époque, un tableau comparatif est proposé entre le comportement de l'opinion face à la révolution de 1830 et, plus tard, en 1848. Cette perspective nous permet d'observer, à travers une étude de cas, à savoir, la réception du libelle antidémocratique de François Guizot, le modus operandi de la classe politique dans la promotion de la propagande antirévolutionnaire, en même temps que l'image du juriste français et l'idéologue sera réhabilité dans une clé opposée à celle appréhendée en 1830. Autrement dit, en tant que paladin des libertés constitutionnelles, le doctrinaire français devient un adversaire viscéral du suffrage universel et des luttes sociales, en un seul terme, de ce qu'il qualifie « d'idolâtrie démocratique ».

MOTS-CLFES : Printemps des Peuples; Révolution du Pernambouc; François Guizot; Démocratie.

\section{INTRODUÇÃOO}

Em 23 de outubro de 2019, o ministro José Celso de Mello Filho, em resposta aos ataques e às manifestações de ódio à justiça brasileira por parte de alguns partidários da extrema-direita, proferiu um discurso em favor da república democrática, lembrando que a mesma foi constituída

sob alguns pilares que não podem ser ignorados, como a liberdade, a solidariedade, o pluralismo político, o convívio harmonioso entre as pessoas, a livre e ampla circulação de ideias e opiniões, o veto ao discurso de ódio, o repúdio a qualquer pensamento indecoroso e discriminatório, o respeito às diferenças e a observância aos direitos fundamentais ${ }^{2}$.

O lugar de fala desse ilustre membro do Supremo Tribunal Federal (STF) não poderia ser outro, senão o de defesa da ordem constitucional. Ao fundamentar seus argumentos nos "pilares" da república, ele nos remete aos mesmos princípios fundados em 1789, os quais serão objeto de reflexões, revisões e de disputas nas revoluções que eclodem na França em 1830, 1848 e 1871, com seus reflexos em todas as partes tocadas pelas "francesias".

\footnotetext{
${ }^{2}$ https://brasil.elpais.com/brasil/2019/10/23/politica/1571829591_815096.html
}

Jangada | ano 9, nr. 17, jan/jun, 2021 | ISSN 2317-4722 


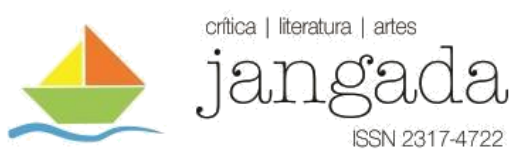

Cumpre ressaltar que se a liberdade e a fraternidade se colocam como os "pilares" da república, como o quer o ex-decano do STF, a igualdade sempre constituiu o elo mais frágil nos debates que nortearam os caminhos da república liberal ${ }^{3}$. Enquanto a liberdade e a fraternidade faziam sua fortuna nas revoluções que demarcaram o longo século XIX, a igualdade seguia seu curso no campo difuso das utopias românticas, convertendo-se em doutrina entre socialistas, comunistas e anarquistas, nas revoluções de 1848 e 1871, até ganhar corpo na Revolução Russa de 1917, a primeira de um novo século que tomava de assalto aos liberais o protagonismo nas lutas políticas internacionais (SECCO, 2020).

O presente estudo se volta justamente para um desses momentos-chaves da história universal, no qual os princípios da liberdade, igualdade e fraternidade fizeram eco no Brasil, em uma conjuntura marcada pelo caráter fortemente conservador do gabinete do Império ${ }^{4}$, em oposição aos radicalismos e rebeliões que se espalhavam no nordeste do país. Referimo-nos às Revoluções de 1848, cujos movimentos fizeram emergir os nacionalismos, não sem antes colocar em cena o povo e as palavras de ordem - democracia, igualdade, soberania - que demarcaram o espaço da política na segunda metade do século na Europa, com suas reverberações em nosso país.

Com base nessas premissas, propõe-se uma cartografia dos discursos e das reações dos brasileiros frente a este evento que destruiu a monarquia constitucional francesa e abalou as estruturas do antigo regime que ainda persistiam no velho continente. Nosso olhar se volta para as manifestações de literatos, com especial atenção para o debate que se coloca na imprensa da época, buscando analisar em que medida a Primavera dos Povos surge como uma inspiração para os movimentos sociais, ao mesmo tempo que ascende, no cerne das classes dominantes e dos segmentos conservadores, o medo e o desejo de reação. Antes de nos voltarmos para 1848, interessa revisitar a produção historiográfica sobre a recepção das ideias de revolução no Brasil, particularmente no que tange aos estudos sobre os movimentos emancipacionistas que

\footnotetext{
${ }^{3}$ Referindo-se ao liberalismo brasileiro, tal como ele se expressa entre algumas vozes dominantes nos anos de 1830/40, escreve Adorno: "Característico daquela época, o gosto pela liberdade de poucos sufocou o grito pela condição de igualdade de muitos. A liberdade associou-se à modernização e ao progresso; a democracia, à anarquia" (Adorno, 2019, p. 54).

${ }^{4}$ Durante o Segundo Reinado, a presidência do Conselho de Ministros foi ocupada por políticos vinculados ao Partido Liberal em 17 oportunidades, contra 15 do Partido Conservador. Porém, os conservadores mantiveram a presidência do Conselho por 27 anos, enquanto os liberais mantiveram o poder por 15 anos. A ascensão dos conservadores se deu justamente com a posse de Pedro Araújo Lima (Gabinete Olinda), em 29 de setembro de 1848. O Partido Conservador se manteve no poder até maio de 1862. Este período ficou conhecido na historiografia brasileira como "o regresso conservador" (HOLANDA, 2010).
}

Jangada | ano 9, nr. 17, jan/jun, 2021 | ISSN 2317-4722 13 | P á g in a 


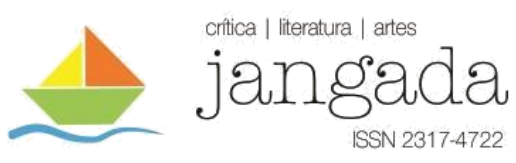

eclodiram no final do século XVIII e início do XIX, bem como seus desdobramentos no debate sobre a presença francesa no ideário político nacional. Finalmente, a análise se detém sobre alguns aspectos da circulação de livros e os repertórios de leituras entre os nacionais, na perspectiva de compreender o papel da economia dos impressos, com seus diferentes suportes e gêneros editoriais a serviço da causa da revolução ou da reação àquele último grito das utopias românticas, ou mais um capítulo de "aprendizado da República" (AGULHON, 1991). Neste ponto, daremos especial realce à difusão do libelo A Democracia na França, de François Guizot (1787-1874), cuja tradução em português, destinada ao leitor brasileiro, deve ser compreendida como uma estratégia de sufocar os ímpetos sufragistas que emanavam da Revolução Praieira (1848-1849), em Pernambuco.

\section{8-1830-1789: ATITUDES POLÍTICAS E FORMAS DE PENSAMENTO}

A Revolução de 1848 eclodiu em Paris, na noite de 23 de fevereiro, quando o povo tomou as ruas e exigiu a destituição do rei Luís Filipe (1773-1850). Um governo provisório foi então formado por ministros que passaram a conduzir o país por meio de um órgão colegiado republicano. O poeta Lamartine (1790-1869), nomeado para a pasta das relações exteriores, revestiu-se logo da figura do grande tribuno, arauto da liberdade.

Não demorou muito tempo para que os ventos revolucionários se espalhassem por toda a Europa. Lutas civis sangrentas se instalaram nos estados germânicos, na península itálica e no império Habsburgo. Por sua abrangência geográfica, mas, também, pela adesão de diferentes setores da sociedade àquele que foi, talvez, o último grito romântico em nome da liberdade, igualdade e fraternidade, a Primavera dos Povos se tornou um marco tanto na história política, quanto na literária (OEHLER, 1999).

Esses eventos foram estampados na imprensa carioca com relativo atraso, ou seja, apenas no mês de abril, causando grande celeuma. Passemos à leitura do noticiário, tal como divulgado pelo Jornal do Commercio:

Chegou hontem de Falmouth, com 36 dias de viagem, o paquete inglês Crane; inesperadas e da mais transcendente importancia são as noticias que nos traz. Acabou a monarchia em França, fugio para Inglaterra toda a família real, proclamou-se a republica! O governo de Luiz Philippe, que se julgava tão enraizado, cahio sem que uma só voz se levantasse em seu favor sem que em 


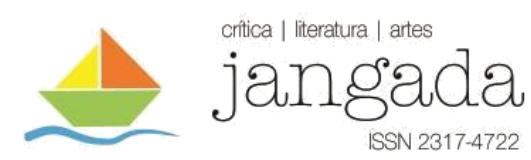

todo o reino um só braço se erguesse para defendê-lo! Nos dias 22 e 23 de fevereiro, alguns grupos que percorrêrão as ruas da capital gritando: - Abaixo Guizot! Viva a reforma! - forão atacados pela guarda municipal, e correu o sangue: mas no dia 24 a população de Paris, em massa, sahio a campo, a guarda nacional fraternizou com o povo, e a tropa de linha recusou bater de contra seus concidadãos. Restava só em atitude hostil a pequena força que guarnecia o palácio das Tulherias, onde se achava toda a família real. O povo marchava para atacar esse ultimo bastião da realeza. $\mathrm{O}$ resultado do conflito não podia ser duvidoso. A familia real fugio, evitando assim um derramamento de sangue inutil, e a dynastia de Luiz Philippe cessou de reinar em França.

O governo republicano foi proclamado imediatamente em todo o reino [...]. (Jornal do Commercio, 12 de abril de 1848, p. 2).

Esse é apenas o resumo de um longo relato que ocupa toda a primeira página do tabloide, em cinco colunas cheias. Sabemos que o Jornal do Commercio foi a maior folha circulante no Rio de Janeiro daquela época e, também, a mais longeva ${ }^{5}$. O Correio Mercantil, segundo título em tiragem e alcance na Corte e nas províncias, antecipou-se ao concorrente em um dia. Porém, divulgou a novidade com muito mais parcimônia, ao substituir a crônica pela opinião:

Hoje é a conversão de todas as classes, de todos os círculos, de cada um cidadão, o passo que acaba de dar a França, repelindo ousada a monarquia constitucional representativa para adoptar a forma republicana, em seu viver de nação: e em verdade, se houvéssemos de emitir o nosso pensar de jornalista consciencioso; se houvéssemos de tomar à peito, esta questão gravíssima, importante, e mais que muito vital para a sorte futura de um povo, agora e sempre pronunciaríamos contra a actual revolução franceza $(O$ Correio Mercantil, 11 de abril de 1848, p. 2) .

\footnotetext{
${ }^{5}$ A Typographia Imperial e Constitucional de J. Villeneuve e C. foi adquirida de Pierre Plancher, fundador do Jornal do Commercio do Rio de Janeiro. Em 1848, quando em sua firma se contavam três impressoras mecânicas, quatro manuais e oitenta empregados, ele era, de longe, o maior impressor da cidade. Seus principais competidores foram a Typographia Nacional (com uma impressora mecânica, uma manual e 62 empregados); Paula Brito (uma impressora mecânica e seis manuais); Laemmert (uma mecânica e seis manuais); e as impressoras do Correio Mercantil e do Correio da Tarde (cada qual com uma mecânica e duas manuais)" (HALLEWELL, 2012, p. 160).

${ }^{6}$ Todos os destaques marcados nas citações são nossos.
} 
O Brasil não será menos direto ao defender seu parti pris:

Política Geral. A Republica franceza. Um immenso acontecimento acaba de realizar-se em França: a republica está proclamada, Luiz Philippe e sua família acham-se na Inglaterra; o rei das tranqueiras, depois de haver completamente esquecido a sua origem e abusado da paciência dos povos, teve de sucumbir á immensa manifestação popular, quasi sem defensores!!

E se dos fatos recentes urgia tirar algum ensinamento, escreve o articulista, sem titubeios:

Era mister uma concessão, era mister alargar a base eleitoral, admitir ao menos a inteligência a par do dinheiro no corpo eleitoral. Luiz Philippe não reconheceu essa necessidade; entendeu que uma massa de perto de 35 milhões de homens podia ficar ainda sob a tutela de uns 300.000 eleitores, em grande parte empregados públicos. Indicios lhe não faltaram de que cumpria ceder: a guarda nacional de Paris de cuja força tinha sido o seu principal apoio nos dias da revolta o havia abandonado; Paris elegera 12 deputados oposicionistas! ... Luiz Philippe e Guizot não cederam e fizeram pela sua maioria condemnar os banquetes reformistas, quizeram oppor-se-lhes pela força... e hoje a França é republica!! A direção do movimento popular e da opinião publica escapou aos chefes menos moderados do partido dynastico, ao proprio Odilon Barrot e lá foi parar ás mãos da mais extrema esquerda, Ledru-Rollin e Duport de l'Eure! ( $O$ Brasil, 12 de abril de 1848).

A palavra de ordem se direcionava, certeira, ao cenário político brasileiro: à oposição entre as províncias e a Coroa somavam-se as intrigas, na Corte, entre exaltados e conservadores, que buscavam, em lugar da negociação, a alternância do poder ${ }^{7}$. Esse quadro se tornava ainda mais ameaçador diante das revoltas provinciais que, nascidas na Regência, estavam longe de esmorecer os ânimos, a tomar pelo exemplo do Partido da Praia, no Recife. Justiniano José da

\footnotetext{
${ }^{7}$ O gabinete conservador, como assinalado anteriormente, será empossado em 29 de setembro de 1848. Parece exato afirmar que há correspondências entre sua vitória e os sucessos da reação no quadro político francês. Amaro Quintas observa que a mudança de direção das Jornadas de 1848 após o massacre de 23 a 26 de junho nas ruas de Paris mudam o tom e os humores dos políticos conservadores brasileiros. Todavia, a Revolução Praieira, que rebenta em novembro, desperta as autoridades da Corte quanto ao perigo das vagas revolucionárias (QUINTAS, 1967).
}

Jangada | ano 9, nr. 17, jan/jun, 2021 | ISSN 2317-4722 


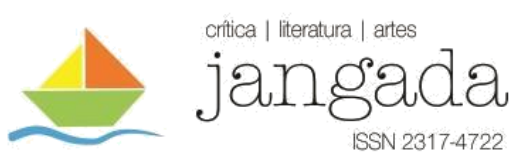

Rocha (1812-1862), redator-chefe do jornal O Brasil, um "conservador convicto" (HoLANDA, 2010, p. 43), faz dos eventos de Paris e da Europa uma fonte de aprendizado, não exatamente da república, mas de um regime monárquico fundado no princípio do equilíbrio das forças ${ }^{8}$.

No decurso de 1848 e 1849, a imprensa brasileira se divide entre os sucessos da política francesa - ou melhor, europeia - e uma nova revolução eclode no Recife, em novembro daquele mesmo ano. O espectro da Revolução atravessara uma vez mais as torrentes do Atlântico. E, como afirma o redator do Mercantil: "agora e sempre pronunciaríamos contra a actual revolução franceza" (O Correio Mercantil, 11 de abril de 1848, p. 2).

Sabemos que desde os movimentos de emancipação, nos estertores do antigo sistema colonial, as imagens da Revolução se imprimiram de forma indelével na vida política brasileira. De um lado, a Independência dos Estados Unidos, em 1779, de outro, a Revolução Francesa, de 1789, cujas matrizes intelectuais alimentavam a imaginação e os ímpetos separatistas de muitos dos ilustrados luso-brasileiros. As torrentes de ideias, de livros e de jornais, mas também de homens que atravessaram, nos dois sentidos, o grande mar, foram mapeadas por toda uma produção historiográfica que se pôs a refletir sobre as "revoluções atlânticas" (GODECHOT, 1978). No entanto, as ideias de Revolução e as ações políticas, como bem o demonstra Carlos Guilherme Mota (2008), tinham seus limites na própria estrutura do sistema colonial, o que se evidencia nas diferentes posturas, de modo geral recalcitrantes, dos "revolucionários" brasileiros, protagonistas da Inconfidência Mineira (1789), da Conjuração Bahiana (1798), da Inconfidência Carioca (1794) e da Inconfidência Pernambucana (1801), em relação aos temas que lhes eram mais caros, a saber, a propriedade, a escravidão, o nacionalismo e a própria ideia de revolução como uma ruptura total com o status quo. Isso ocorre justamente porque, como afirma Mota, "na base de qualquer processo desencadeado em áreas coloniais, a Revolução trouxe, no transcorrer de todo o processo, a marca insuperável da situação colonial. O homem, o ser colonial" - continua o autor - "participou das transformações já contaminado pela determinação mencionada" (MOTA, 2008, p. 24-25).

\footnotetext{
${ }^{8}$ Tal como na França de Luís Filipe, no Brasil "o voto, durante toda a fase imperial, foi censitário; exigiu a Constituição [de 1824] - e, consequentemente, as Instruções que aqui analisamos também a exigiram - a renda de $100 \$ 000$ para o Votante e de $200 \$ 000$ para o Eleitor". Em 1846, a desvalorização da moeda fez duplicar a renda fixada: 200 para o Votante e 400 para o Eleitor. É importante observar a distinção entre o Votante, aquele que vota apenas em primeiro grau, e o Eleitor, dotado de maior posse, vota em segundo grau. "A lei Saraiva, fundindo Votante e Eleitor, conservou o censo estabelecido para o primeiro" (PORTO, 2002). As questões históricas, que se fundam ou derivam desse sistema, foram bastante esmiuçadas pela historiografia, como podemos apreender no volume dedicado ao período de História Geral da Civilização Brasileira: O Brasil Monárquico (1987).
}
Jangada| ano 9, nr. 17, jan/jun, 2021 | ISSN 2317-4722
17 | P á g in a 


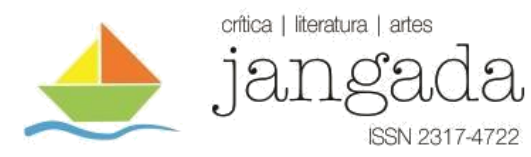

E se $o$ ser colonial já não se apresenta como uma constante de longa duração após o movimento de Independência (1822), a hipótese permanece válida para a análise da recepção das revoluções francesas de 1830 e 1848. Isso porque a ideia de Revolução, já bastante cristalizada na opinião pública após os desdobramentos de 1789, deverá se ajustar a novas formas de pensamento dominantes e a novas condicionantes de classe em uma sociedade profundamente marcada pelo patriarcalismo e o escravismo.

Essa questão se torna mais clara quando se compara a reação da opinião pública brasileira no que toca aos eventos de 1830 e de 1848.

Lembremos que em julho de 1830 ocorre a Revolução que derruba a dinastia Bourbon e instala não uma república, mas uma nova monarquia de compromisso: o juste milieu. ${ }^{9} \mathrm{O}$ exemplo francês põe os regimes monárquicos europeus sob alvo de críticas, cujos ecos reverberam no Brasil. Segundo Oliveira Martins, D. Pedro I (1798-1834) queria se tornar um George Washington (1732-1799), sem, contudo, deixar de ser um monarca. Na sua visão de governo, "a liberdade era um presente, e não o reconhecimento de um direito popular" (MARTINS, 1952, p. 46).

Em São Paulo, a notícia da Revolução de Julho chegou no mês de outubro e, diferente da recepção reservada (ou, mesmo, contrariada) que mereceram os eventos de 1848, ela foi sinceramente festejada pelos estudantes da Academia de Direito, que se regozijaram com a boa nova e fizeram demonstrações de simpatia ao liberalismo triunfante (DEAECTO; SECCO, 2014). A ruidosa manifestação levou o ouvidor da cidade, Candido Japyassu (1799-1861), a ordenar uma devassa, notícia que agitou ainda mais os humores locais. Em O Observador Constitucional, jornal redigido pelo italiano Libero Badaró (1798-1830), não foram poupadas críticas explícitas ao ouvidor. Também a Câmara Municipal protestou contra Japyassu, enviando ofício ao vice-presidente de São Paulo, no qual alegava o perigo de "sublevação" se a ordem fosse cumprida. Afinal, não se justificava uma devassa só porque o "governo tirânico que pesava sobre a França fora destruído" (Registro Geral da Câmara, São Paulo, 8 de outubro de 1830).

As demonstrações dos estudantes da Academia de Direito foram as primeiras de uma série de incidentes que colocaram em confronto direto os partidários do liberalismo e os defensores do absolutismo orquestrado por D. Pedro I. Em São Paulo, elas culminaram no

${ }^{9}$ Juste milieu ou regime de compromisso caracterizado, em 1830, pelo suposto fim das lutas de classes (de acordo
com Guizot). O período aberto em 1830 seria o de equilíbrio depois dos excessos da Revolução e da Restauração. Jangada | ano 9, nr. 17, jan/jun, 2021 | ISSN 2317-4722 18 | P á g i n a 


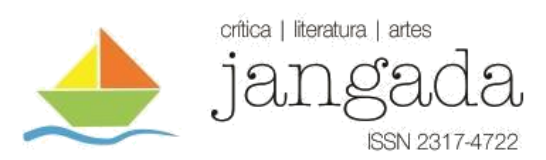

assassinato do jornalista italiano Libero Badaró, na noite de 20 de novembro de 1830. De modo mais profundo, conduziram à abdicação do imperador, em 7 de abril de 1831 .

É verdade que a crise do Primeiro Reinado deve ser compreendida como o sintoma de um movimento mais amplo de oposição aos regimes absolutistas iniciado pela Revolução Francesa, o qual adquire contornos radicais em meados dos anos de 1830 e um desfecho dramático em 1848. Essas crises demarcam diferentes conjunturas da política liberal, com suas idas e vindas, avanços e recuos consubstanciados ora no terror jacobino, ora na reação termidoriana (HoBSBAWM, 1996). Nesse sentido, a Restauração francesa (1815-1830) havia gerado nova crise que precisava encontrar uma solução moderada, ou seja, uma monarquia liberal, leia-se, burguesa, tal como ela se apresenta com a ascensão da casa de Orléans.

Tal perspectiva se apoiava, inclusive, em uma escrita dominante sobre a história da Revolução de 1789, assentada sobre as mesmas bases liberais vitoriosas na Monarquia de Julho. Todavia, durante a Restauração nada disso parecia óbvio. Naqueles tempos difíceis de centralização e de forte censura, restava aos ideólogos liberais, que conformaram uma primeira geração de historiadores da Revolução, o refúgio no pensamento e na escrita. "Escrevam livros", teria aconselhado Royer-Collard (1763-1845) a jovens promissores do porte de Mignet (1796-1884), Thiers (1797-1877) e Guizot. Vale dizer, um repertório bem familiar aos leitores brasileiros, como pudemos constatar noutros estudos, pautados nas coleções de bibliotecas particulares, a partir dos bens arrolados nos inventários post-mortem (AIRES, 2018), mas também nas referências amiúde exibidas pela imprensa, por meio de recensões, citações, epígrafes e anúncios de vendas de livros (DEAECTO, 2019). Hobsbawm assinala, não sem um ingrediente de ironia, que Alphonse de Lamartine (1790-1869) publicou, em 1847, sua Histoire des Girondins, uma ode ao herói Mirabeau (1749-1791), como a "desencorajar os excessos dos jacobinos" (HoBSBAwM, 1996, p. 81).

1848 representa, nesse sentido, uma nova fissura do projeto liberal. A burguesia será momentaneamente alijada do poder e as palavras de ordem, aparentemente emudecidas, vêm à tona: república social e democracia, sustentadas, ambas, pelo sufrágio universal. Assim o princípio da igualdade vem assombrar, como um espectro, a ordem vigente. Ou seja, nada poderia ser mais inquietante para os defensores do voto censitário, na França e alhures. Como adverte o articulista d'O Brasil, na passagem citada: "Era mister uma concessão, era mister alargar a base eleitoral, admitir ao menos a inteligência a par do dinheiro no corpo eleitoral". 


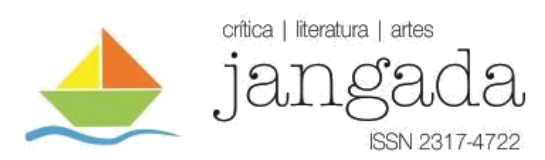

Nesse ponto, o esprit quarente-huitard irrompe como o esprit jacobin redivivo. É preciso compreender o quanto as notícias sobre os avanços das revoluções europeias funcionavam como um fermento para a imaginação e a tomada de consciência tanto do cidadão comum, quanto do jovem aspirante à carreira política brasileira, como o eram os estudantes das faculdades do Recife e de São Paulo, como bem observou Adorno (2019) em seu estudo clássico. Nesse microcosmo extremamente fecundo vamos encontrar a figura do jovem leitor e orador Álvares de Azevedo (1831-1852) a justificar ao pai que o discurso por ele proferido na "sessão de instalação da Sociedade Acadêmica - Ensaio Philosophico - a 9 de maio de 1850, "nada tinha de revulsivo" (AZEVEDO, p. 1942). Notemos que em maio de 1850, já corriam as notícias do refluxo das vagas revolucionárias na Europa (e em Pernambuco). Então, o que reclamava o poeta, que tantas aflições provocaram em seu pai? Nada além de uma filosofia e de uma poesia nacional. Nas suas palavras: "Sem uma filosofia, sem uma poesia nacional, como quereis uma nação? A copia lívida do que vai pelo mar além poderá ser o sangue de uma nação? O parasitismo scientífico poderá ser condição de vida para a intelligencia de um povo?” (PIRES, 1942, p. 424).

No fundo, o esprit quarante-huitard, embora fizesse emergir os princípios universais da fraternidade entre os povos, não descuidava de suas pulsões nacionalistas. Era preciso transformar as matrizes intelectuais d'outre-mer em seiva nacional ${ }^{10}$. Donde se depreende o radicalismo possível do jovem estudante que vivenciou suas primeiras experiências políticas no burgo planaltino, entre 1848 e 1851. Esse interesse pelas coisas de França se reflete nas preferências de leituras do poeta nesses anos revulsivos, a começar pelos livros que ele encomenda, por carta, à mãe, residente na Corte.

Na missiva de 7 de junho de 1848, Álvares de Azevedo anota, sob a forma de um post scriptum atravessado no texto:

Ainda não recebi - até agora - á chegada do Correio - as encommendas Espero ancioso os Girondinos q. vmcê em confirmação a uma antiga promessa

\footnotetext{
${ }^{10}$ Esse mesmo comportamento será notado por Espagne, no estudo que faz sobre as traduções de filósofos franceses na França. E, mais do que a cor nacional, era preciso traduzir e se apropriar de um pensamento dentro de chaves específicas. O autor observa, por exemplo, que a recepção de Fichte (1762-1814), na França, ocorre em chaves diferentes, conforme os intelectuais ou as coteries que se apropriam de seus escritos. Para Edgard Quinet, o filósofo alemão se apresenta como o próprio espírito da Convenção, enquanto nos anos da Monarquia de Julho, "a referência a Fichte consistia, precisamente, em refutar a herança revolucionária em proveito do espiritualismo". Victor Cousin e seus discípulos devem ler e difundir o filósofo alemão, por meio de suas traduções, nessa mesma chave espiritualista (ESPAGNE, 1999, p. 21-34).
}

Jangada | ano 9, nr. 17, jan/jun, 2021 | ISSN 2317-4722 


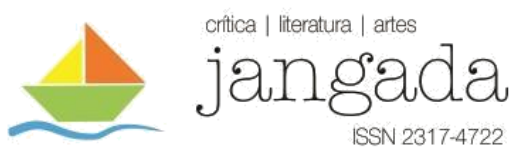

bem me poderia ter mandado de presente - espero q. a promessa do retrato se realise ao receber vmcê o meu retrato e não dê em troca como outras ... da Nhãnhã e - (talvez se eu fosse má língua o diria) - suas. (AZEVEDO, 1976, p. 82)

Um ano mais tarde, precisamente em 7 de julho de 1849, ele volta a fazer nova solicitação, demonstrando-se não somente afinado com as edições que apareciam na França, mas também muito interessado pela historiografia política francesa:

Quanto a mim quero lhe fazer 2 encommendas tambem - um exemplar da Démocratie en France de Guizot - e do Raphael de Lamartine q ahi nos jornais se annunciarão um a 200 rs. ${ }^{11}$ e o outro 800. (AZEVEDO, 1976, p. 84)

Leituras que, no limite, denunciavam a inquietude e a curiosidade intelectual de nosso poeta. Porém, se urgia justificar ao pai, como o fez em maio de 1850, que suas teorias nada tinham de revulsivas, é porque Álvares de Azevedo talvez soubesse que os ecos das revoluções ressoavam por todas as partes. Afinal, como havia anotado Joaquim Nabuco, em referência às memórias de seu pai, "a proclamação da república em França havia agitado o nosso mundo político em suas profundezas (NABUCO, 1936, t. 1, p. 67). Não era de São Paulo que ele olhava a vida política, mas do velho Recife, o que mudava tudo.

Antes de nos voltarmos para a província do Norte, cumpre lembrar uma experiência radical no Sul do país, onde o fourierismo se fez presente. Dois falanstérios foram criados em Santa Catarina: o primeiro, junto à Península do Saí; o segundo, em Palmital. Segundo Adelaide Gonçalves (2004), em julho de 1841 a Câmara de Deputados aprovou um empréstimo de 64 contos de réis para apoiar o início do projeto.

Mas no Norte essas manifestações tiveram mais substância. Notemos que antes de eclodir a Praieira, o Recife conhecera a ação utópica do engenheiro francês Vauthier (18151901). O periódico O Globo imitava o homônimo sansimoniano parisiense (FREYRE, 1960). Em 1844, o jornalista Antônio Pedro de Figueiredo (1814-1859) publicou, na revista $O$ Progresso, informações sobre a Liga dos Justos, da qual Friedrich Engels (1820-1895) fazia parte. Neste mesmo ano de 1844 publicou-se O Socialista da Província do Rio de Janeiro (GALlo, 2009). Mas pouco havia nele de traços do socialismo científico. No editorial ao

\footnotetext{
${ }^{11}$ Aqui há uma incorreção do poeta ou da transcrição da manuscrito, pois como podemos conferir adiante (p. 17), o livro foi anunciado nos jornais cariocas por dois mil réis.
}

Jangada | ano 9, nr. 17, jan/jun, 2021 | ISSN 2317-4722 21 | P á g in a 


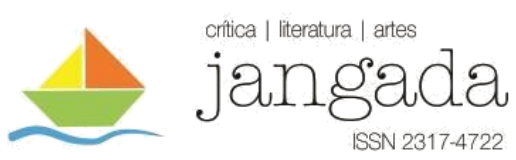

primeiro número d'O Socialista, M. G. de S. Rego explica o significado do nome como referente a

todo o aperfeiçoamento de que for suscetível a sociedade, provincial, nacional e universal, quer na parte moral, quer na material, em que naturalmente está dividida a vivenda humana no mundo terreno. Assim, pois o socialista tratará de agronomia prática, economia social, didática jacotista, política preventiva e medicina doméstica, e sobretudo do socialismo, ciência novamente explorada, da qual basta dizer, que seu fim é ensinar aos homens a se amarem uns aos outros ( $O$ Socialista da Província do Rio de Janeiro, $\mathrm{n}^{\circ} .1,1$ de agosto de 1845).

No mesmo Recife, anota Amaro Quintas,

circulou um jornal intitulado Kossuth, nome do herói nacional húngaro de 48, do quarante-huitard magiar, fato que, quando por mim narrado, causou ao escritor húngaro Paulo Ronai profunda admiração, afirmando-me considerálo acontecimento único em todo o mundo (QUINTAS, 1967, p. 307).

O primeiro livro editado no Brasil sobre o socialismo foi do general José Ignacio de Abreu e Lima (1794-1869), Socialismo (Recife: Typographia Universal, 1855), embora se questione sua relação com as ideias radicais que habitavam as mentes de alguns europeus.

Porém, estes esforços pontuais foram sufocados, na medida do possível, pelos órgãos de opinião dominantes. É o que vemos na ação orquestrada da imprensa, da livraria e da edição em prol da ampla difusão de um livro paradigmático, que prometia colocar uma pá de cal nas ilusões democráticas e sufragistas alimentadas pela Primavera dos Povos. A trajetória editorial de De la Démocratie en France, de François Guizot, no Brasil, deve ser analisada dentro da torrente reacionária que vive o mundo a partir de junho de 1848 e, com maior vigor, durante o inverno rigoroso - pelo menos, na Europa - de 1849.

\section{"Remedio Poderoso Para Combater as Paixões Deletereas"}

Aos Brazileiros

A noticia dos recentes e desastrosos accontecimentos de Pernambuco, não podia deixar de affligir-me e de excitar meu patriotismo.

Já que a minha obscuridade não dá peso aos meos conselhos, permitti-me que vos ofereça, vertido em portuguez, este notável escripto de um dos mais eminentes escriptores contemporaneos, cuja probidade severa, cujos sentimentos profundamente liberaes, são reconhecidos por amigos e inimigos.

\footnotetext{
Jangada | ano 9, nr. 17, jan/jun, 2021 | ISSN 2317-4722

22 | P á g in a
} 
A vulgarização deste livro será um remedio poderoso para combater as paixões deletereas que se conjugarão para attacar a sociedade no que ella tem de mais inviolavel e de mais santo.

As doutrinas delle estão sancionadas pela experiência da revolução franceza de 1848. Já não é permitido nutrir ilusões: nenhum homem honesto e consciencioso, poderá deixar de reconhecer que o único governo capaz de garantir a liberdade, é o monarquico representativo, pelos elementos d'ordem que lhe dá o poder hereditario. E sem ordem não pode haver liberdade; a anarquia foi sempre precursora do despotismo.

Acceitai pois esta pequena lembrança como tributo de sincero patriotismo: possa a pureza da intenção, e a importância do motivo servir de sufficiente desculpa à ouzadia da ação.

José Lucio Correia

Pariz, 12 de fevereiro de 1849 (GUIZOT, 1849, p. V-VII)

O autor do prefácio à edição brasileira de François Guizot se situa na fina camada de capitalistas e proprietários aflitos com mais uma revolução que tomara de assalto as ruas do Recife e se alastrou por toda a província e suas vizinhanças ${ }^{12}$. Na época da publicação de Démocratie, ele morava em Paris, onde mantinha, na rue de Trévise, um escritório especializado nos serviços de comissão e representação. Seu nome figura entre os negociantes que tiveram presença ativa nos programas de modernização de Pernambuco, entre 1837 e 1844, durante a administração de Francisco do Rego Barros, Conde da Boa Vista (1802-1870), de quem era amigo. Nesses tempos, escreve Izabel Marson,

uma política de coalisão tornou viável a reunião de liberais e conservadores, cidadãos de diferentes posições na sociedade - bacharéis, senhores de engenho, produtores de algodão e comerciantes, encabeçados os primeiros por Antonio Francisco de Paula Holanda Cavalcanti (1797-1863) e os segundos por Rego-Barros (MARSON, 2009, p. 16).

\footnotetext{
12 Também afligiu seu espírito, por essa mesma época, as notícias que na França circularam sobre o desenvolvimento de novas técnicas de produção do açúcar a partir da beterraba, o que representaria, como de fato representou, uma concorrência sem par para as exportações brasileiras. É o que lemos no artigo de sua autoria, publicado em Pernambuco e reproduzido em diferentes folhas do norte, sob o título "Fabrico do Assucar" (Publicador Maranhense, 29 de maio de 1844).
}

Jangada| ano 9, nr. 17, jan/jun, 2021 | ISSN 2317-4722 23 |P á g in a 


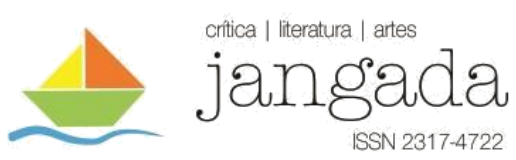

Os projetos de infraestrutura, remodelação urbana e transportes foram confiados a uma equipe de engenheiros oriundos da École de Ponts-et-Chaussées de Paris, sob a chefia de Louis Léger Vauthier (1815-1801). Fora o "Sr. Correia" responsável por todas as negociações, que consistiram em arregimentar o corpo técnico francês e promover sua transferência para o Recife $^{13}$. Além disso, era ele o responsável pela expedição, da Europa, dos materiais e instrumentos necessários para as obras implementadas na capital e na província ${ }^{14}$.

A estabilidade política alcançada nesse período e a recuperação da economia açucareira, com o consequente aumento das exportações, conformaram um ciclo virtuoso da sociedade pernambucana, do qual nosso personagem tirara grandes proventos. Porém, como o desenvolvimento material vai de par com o progresso mental, não demorava o tempo em que a chamada "política de reorganização e do futuro" esbarrasse com novas ideias e diferentes configurações partidárias. A revista $O$ Progresso, para a qual colaborou Vauthier testemunha bem essa relação entre o avanço material e mental nas sociedades. Ela abraçou o socialismo francês, ou, pelo menos, um certo socialismo, como observa Gilberto Freyre, no qual circulava um amálgama das ideias de Victor Cousin, Fourier e Saint-Simon. O principal arauto dessas ideias, amigo do engenheiro francês, foi Antonio Pedro de Figueiredo (1814-1859), diretor da revista entre 1846 e 1848 (FREYRE, 1960, t.2, p. 343).

Por seu turno, o Partido Nacional de Pernambuco, ou, como se popularizou, o Partido da Praia, nascido de uma dissidência do Partido Liberal, em 1842, teve no jornal Diário Novo seu principal meio de luta, sendo representado por diferentes setores da sociedade: negociantes, proprietários de engenhos, bacharéis oriundos da Faculdade de Olinda e caixeiros, que conformavam um amálgama singular entre lideranças dissidentes dos Partidos tradicionais (Conservador e Liberal). Não vamos retomar todos os eventos que fizeram os partidários da Praia a converter um programa de caráter conservador e reformista em uma revolução de cunho popular, como a que eclodiu no Recife, de novembro de 1848 a abril de 1849 - ou novembro, considerando a resistência armada de Pedro Ivo (1811-1852).

\footnotetext{
${ }^{13} \mathrm{O}$ engenheiro francês anota em seu diário, enquanto esperava os carregamentos para o embarque no porto do Havre, em direção ao Recife: "[18 de julho de 1840] Novas discussões com os armadores e os representantes do Sr. Correia para conseguir colocar os caixotos de livros e instrumentos. Longos e insípidos debates, argumentação frívola. Acabaram cedendo diante de minha declaração de que estava resolvido a partir por um paquete inglês. Obtive enfim boas acomodações a bordo" (FREYRE, 1960, t.2, p. 523-524).

14. "No fim do ano de 1843 chegava a parte mais importante da estrutura: o fio de arame chegado da Inglaterra para a ponte suspensa que em Caxangá e juntamente uma cópia da fatura respectiva mandada por José Lúcio Correia”. Esta e outras transações pesaram sobre ele e o governo provincial, acusados, como foram, de corrupção. Porém, tais fatos fogem ao escopo da pesquisa (MAIOR, 2015, p. 156).
}

Jangada | ano 9, nr. 17, jan/jun, 2021 | ISSN 2317-4722 24 |P á g in a 
Interessa assinalar os elementos locais e universais que tornavam as Revoluções de 1848 e, no campo oposto, o libelo de François Guizot, instrumentos de aprendizado para os leitores brasileiros ${ }^{15}$. Nesse aspecto, devemos observar que no curso da "guerra civil" que se instalou em Pernambuco, dois projetos tomaram vulto: “ 'a revolta' pensada e organizada pelo Partido da Praia e a Sociedade Imperial, pugnando por uma reforma da monarquia constitucional" (MARSON, 2009, p. 74); e a revolução defendida por Borges da Fonseca (1808-1872), cujos princípios universalistas expressos no Manifesto do Mundo ${ }^{16}$, foram inspirados nas reivindicações parisienses, naquelas já distantes jornadas de fevereiro.

Vencidos os revolucionários e abertos os autos de devassa, as primeiras interpretações dos acontecimentos não demoraram a vir a lume. Izabel Marson procede a uma análise fina da reconstrução dos fatos, segundo relatos impressos por suas principais testemunhas: o relatório minucioso do chefe de polícia Jeronimo Martiniano Figueira de Mello (1809-1878); o discurso condenatório do deputado conservador Antonio Peregrino Maciel Monteiro (1804-1868), proferido na Assembleia Provincial, em 26 de abril de 1849; e a resposta do chefe da deputação praieira Urbano Sabino Pessoa de Mello (1811-1870), que participara da última legislatura (1845-1848). Vencera, naquelas circunstâncias, o discurso da ordem, ou seja, do chefe de polícia.

Compreende-se, nesse sentido, o porquê de uma tradução do texto de Guizot endereçada ao público brasileiro, segundo a perspectiva de José Lúcio Correia. Mas a fortuna do livro tem alcance muito mais abrangente. É o que relata, por exemplo, umas das folhas cariocas que noticiou seu lançamento:

\footnotetext{
${ }^{15}$ Amaro Quintas (1967), sustentará, com notável vigor, que a Revolução Praieira foi a própria expressão do “espírito quarente-huitard”! Poderíamos objetar, à luz de Izabel Marson (2009), que esse espírito habitou parte dos praieiros, o que não diminui o interesse por sua análise.

${ }^{16}$ A interpretação que faz Caio Prado Jr. dos eventos pernambucanos é bastante reveladora de seu parti pris político. Para o autor, o movimento eclode em 1848, em meio ao clima de terror que as revoluções europeias e a onda socialista impingem entre as elites políticas nessa porção dos trópicos. Assim o Partido da Praia tomou as armas em 7 de novembro de 1848: "levantaram-se em Olinda, Igaraçu e outros pontos da província, e marcharam sobre a capital. Como programa apresentou a Praia os seguintes pontos: 1ㅇ - Voto livre e universal do povo brasileiro; $2^{-}$- plena liberdade de comunicar os pensamentos pela imprensa; $3^{-}$- trabalho como garantia de vida para o cidadão brasileiro; $4^{\circ}$ comércio a retalho para os cidadãos brasileiros; $5^{\circ}$ - inteira e efetiva independência dos poderes constituídos; $6^{\circ}$ - extinção do poder moderador e do direito de agraciar; $7^{\circ}$ - elemento federal na nova organização; $8^{\circ}$ - completa reforma do poder judicial em ordem a assegurar as garantias individuais dos cidadãos; 9ํ - extinção do juro convencional; $10^{\circ}$ - extinção do atual sistema de recrutamento". Todavia, o programa foi proclamado apócrifo pelo órgão impresso do movimento e a própria luta perdeu seu fôlego. "A agitação praieira, incapaz de realizar seu ciclo completo, incapaz de propagar a centelha revolucionária através de todas as camadas rebeldes da sociedade, ficando apenas na superfície - escreve o autor - é bem o estertor de agonia do intenso movimento popular que acompanha a independência" (PRADO JR., 1961, p. 79-80).
}

Jangada | ano 9, nr. 17, jan/jun, 2021 | ISSN 2317-4722 25 | P á g i n a 
Um dos acontecimentos mais notáveis, no meio dos extraordinarios acontecimentos que tem ocorrido em França, foi a apparição do livro de Mr. Guizot, - De la Démocratie en France - para se avaliar a avidez com que todos o procurarão ler, basta dizer que em menos de quinze dias se venderão 67,000 exemplares, e que elle foi traduzido immediatamente em inglez, em allemão, em hespanhol, e em italiano (A Sentinela do Povo, Rio de Janeiro, 16 de junho de 1849).

Em pesquisa recentemente publicada, apontamos o aparecimento de 48 edições de Démocratie, tiradas do prelo entre janeiro e junho de 1849, em traduções e versões originais, não raro com reimpressões, em diferentes cidades europeias e americanas, a saber: Paris, Londres, Bruxelas, Liège, Haia, Maastricht, Utrecht, Oslo, Estocolmo, Berlim, Frankfurt a/Oder, Leipzig, Grimma, Breslau, Viena, Madrid, Palma, Nápoles, Turim, Lisboa, Nova Iorque, Cidade do México, Rio de Janeiro... Esta cartografia corresponde a duas tendências: do ponto de vista da economia dos impressos, o sucesso editorial se deve à rede internacional de livreiros que de Paris fazia ecoar seus títulos por todas as partes tocadas pelas francesias; do ponto de vista político, a difusão deve ser compreendida como o esforço das elites locais no sentido de apresentar e promover um programa alternativo às pulsões revolucionárias e sufragistas (DEAECTO, 2021).

A campanha em torno dessa brochura não foi de pouca monta, a tomar pelo exemplo brasileiro. Notemos que antes da edição em livro, Democracia veio a lume sob a forma de folhetim. As reproduções do texto se iniciam em maio e cessam em junho. O programa contempla o calendário exposto na tabela abaixo:

\begin{tabular}{|c|c|c|c|}
\hline \multicolumn{4}{|c|}{ Programa de Edição de Democracia em folhetim, no Jornal Correio da Tarde, maio-junho/1849 } \\
\hline \multicolumn{4}{|c|}{$\begin{array}{l}\text { Cabeçalho } \\
\text { A Democracia em França, por Mr. Guizot. Janeiro de } 1849 .\end{array}$} \\
\hline no. & Data & Capítulos/Títulos & Páginas \\
\hline 397 & Sexta-feira, $18 / 05$ & $\begin{array}{l}\text { [Prólogo] } \\
\text { Cap. } 1 \text { - Causa do Mal } \\
\text { Cap. } 2 \text { - Do Governo na Democracia }\end{array}$ & $1-3$ \\
\hline 398 & Sábado, 19/05 & Cap. 3 - Da República Democrática & $1-2$ \\
\hline 403 & Quarta-feira, 23/05 & Cap. 4-Da República Social & 1 \\
\hline 405 & Terça-feira, 25/05 & $\begin{array}{l}\text { Cont. } \\
\text { Cap. } 4 \text { - Quais são os elementos reais e } \\
\text { essenciais da sociedade em França }\end{array}$ & 1 \\
\hline 408 & Terça-feira, 29/05 & $\begin{array}{l}\text { Cont. } \\
\text { Cap. } 5 \text { - Quais são os elementos reais e } \\
\text { essenciais da sociedade em França }\end{array}$ & $1-2$ \\
\hline
\end{tabular}




\begin{tabular}{|l|l|l|c|}
\hline 411 & Terça-feira, 05/06 & $\begin{array}{l}\text { Cap. 6 - Condições políticas da paz social na } \\
\text { França }\end{array}$ & $1-2$ \\
\hline 413 & Sexta-feira, 08/06 & $\begin{array}{l}\text { Continuação } \\
\text { Cap. 6 - Condições políticas da paz social na } \\
\text { França }\end{array}$ & 1 \\
\hline 417 & Quinta-feira, 14/06 & $\begin{array}{l}\text { Cap. 7 - Condições morais da paz social na } \\
\text { França } \\
\text { Capítulo 8-Conclusão - Fim }\end{array}$ & $1-2$ \\
\hline
\end{tabular}

Ao mesmo tempo que os excertos eram traduzidos e publicados, instaurou-se uma verdadeira batalha de opiniões, pautada no texto de Guizot, por dois dos mais importantes jornais cariocas, os já citados $O$ Correio Mercantil e $O$ Brasil.

Outrossim, foi possível observar que a publicação dos últimos capítulos do texto no pé da página do jornal coincidiu com o lançamento da brochura nas livrarias cariocas. É o que lemos na edição dominical d'O Correio Mercantil:

Agostinho de Freitas Guimarães e Cia. acabão de receber de Paris alguns exemplares desse livro, traduzido em portuguez, com a maior elegancia e pureza, que se achão a venda em sua loja, rua do Sabão, $n^{\circ} \cdot 26$, ao preço de $2 \$ 000$ reis, cada um, encadernado à inglesa, bom typo, bom papel, e com o fac-Símile de Mr. Guizot (Correio Mercantil, dirigido por Rodrigues e Cia., Rio de Janeiro, 3 de junho de 1849, fl.4).

O valor declarado da brochura equivale a um terço da assinatura semestral do Correio da Tarde, jornal que publicava os capítulos em folhetim. Considerando que a folha avulsa custava 120 reis, era evidentemente muito mais barato ler o texto no jornal. Mas, "livro é livro...", diriam os bibliófilos. De fato, a edição brasileira não se distinguia muito dos padrões editoriais e materiais da francesa: mesmo formato, mesmo padrão tipográfico, nos termos do anúncio, "bom typo, bom papel"17. E, o que se apresenta como um diferencial pouco praticado no mercado francês nos anos de 1840-50, mas ainda frequente no Brasil: o volume era encadernado. Ou, como reza o texto, "encadernado à inglesa"18. Assim os caracteres materiais da edição pareciam definir sua clientela, sensivelmente diferente daquela que lia o jornal. Pelo

\footnotetext{
${ }^{17}$ A edição de Victor Masson foi impressa na gráfica das edições Plon, essa importante empresa que deixou suas marcas na conformação de um catálogo deliberadamente conservador, na França, enquanto que a impressão "brasileira", foi realizada na oficina de Thunot, localizada na rue Racine, em Paris.

${ }^{18} \mathrm{Na}$ encadernação à inglesa, ou semi-inglesa, ou meia-inglesa, como é denominada hoje, apenas a lombada é revestida de couro. A pasta é em papel ou outro material. Ocorre, às vezes, das ponteiras das capas virem revestidas com couro. O exemplar da Biblioteca da Faculdade de Direito (USP) apresenta a encadernação original, sendo a lombada revestida de couro e todas as capas em papel, sem ponteiras (FARIA; PERICÃO, 2008, p. 285-286). É possível que a mesma tenha sido feita no Rio de Janeiro, por encomenda do livreiro, para agregar valor à brochura e, portanto, atrair a clientela. $\mathrm{O}$ exemplar da BNF não tem encadernação original.
}

Jangada | ano 9, nr. 17, jan/jun, 2021 | ISSN 2317-4722 27 |P á g in a 


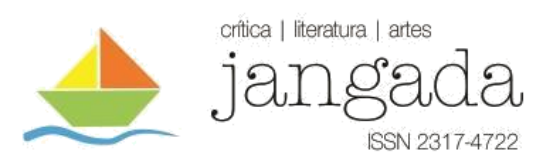

menos, no gosto pela posse do livro, considerando que, diferente da França, a participação do leitor brasileiro na sociedade era muito mais rarefeita. Cumpre notar que os caracteres materiais das edições europeias variam muito em relação à francesa. Na maior parte dos casos, aquelas publicações se assemelhavam muito mais ao gênero panfletário, por sua tipografia cerrada, o uso de papel jornal e o formato relativamente menor, do que as brochuras publicadas em Paris - e a versão impressa em Paris, destinada ao leitorado brasileiro.

Completa esse quadro de revoluções e de reações, o perfil do tradutor da brochura. Sabemos hoje não se tratar de um brasileiro, mas de um português, autor e tradutor de escritos de ocasião que marcaram data no cenário político da época, como se pode inferir da lista que se segue:

1. O Federalista. Publicado em Inglez por Hamilton, Madisson e Jay, Cidadãos de Nova York, e Traduzido Em Portuguez Por *** [José Da Gama e Castro - manuscrito a lápis]. Tomo Primeiro. Rio De Janeiro : Typ. Imp. e Const. de J. Villeneuve e Comp., 1840.

[nova edição] Ouro Preto : Imprensa Official do Estado de Minas, 1896, 3 vol. in-8, de $271+$ III, 292, $250+11 \mathrm{p}$.

2. O Novo Principe, ou O Espirito dos Governos Monarchicos, por *** [José da Gama e Castro - manuscrito a lápis], segunda edição, revista e consideravelmente augmentada pelo autor. Rio de Janeiro : Typ. Imp. e Const. de J. Villeneuve e Comp., 1841.

3. O Novo Carapuceiro, Ou Typos da Nossa Época, por *** [José da Gama Castro - manuscrito a lápis]. Rio de Janeiro: Typ. Imp. e Const. de J. Villeneuve, 1842. in-8 de VIII + 166 p. (PAIVA, 1929).

O tradutor d'O Federalista e autor de panfletos políticos de denodado mau gosto, particularmente pelo abuso que faz de linguagem jocosa, destinada a detratar e a desmoralizar seus opositores políticos, cuja assinatura é amiúde grafada por um misterioso ***, responde pelo nome de José da Gama e Castro. Segundo Inocêncio da Silva:

Doutor em Medicina pela Universidade de Coimbra, onde ele nasceu, nos últimos anos do século XVIII [...]. Lançado por suas conviç̧ões políticas no partido de D. Miguel, ele lhe serviu com dedicação, tendo sido nomeado Físico Mestre do Exército português, juntamente a outras comissões importantes. Após a derrocada política de 1834, ele emigrou, em dezembro e 


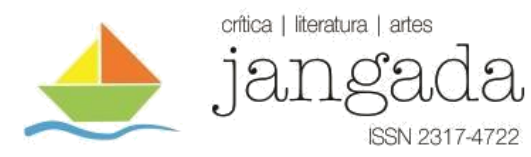

após uma longa digressão através da Europa, decidiu partir para o Brasil. Aportou no Rio de Janeiro no final de 1837, sou da opinião de que tenha permanecido nesta cidade até 1842 , onde se dedicou a trabalhos literários e à imprensa. Uma nova investida na Europa o conduziu a viagens através da França, da Alemanha etc., até que se fixou em Paris, onde vive até nossos dias (SILVA, 1973, tomo IV, p. 358-359). ${ }^{19}$

\section{SOBRE A DEMOCRACIA E A IMPOSSÍVEL IGUALDADE: À GUISA DE CONCLUSÃO}

Não nos enganemos, enfim: A Democracia na França constitui uma análise à moda tocqueviliana, "que se volta com virulência contra a idolatria do sistema democrático" (THEIS, 2008, p. 38). Como temos insistido, a brochura se situa na vaga reacionária que de Paris se lançou por toda a Europa, já no outono de 1848, o que faz do texto de François Guizot uma expressão elaborada e refletida da campanha antisufragista e visceralmente oposta ao socialismo.

Mas esta história não se restringe ao aspecto circunstancial da vida de um livro. $\mathrm{Na}$ verdade, o sucesso editorial de Démocratie nos permite refletir sobre a recepção de François Guizot no Brasil, antes e depois de 1848. Para tanto, tomemos o caso paradigmático de São Paulo, em virtude da importância que a Academia de Direito conferiu à obra do jurista francês e aos eventos que conduziram à vitória de seu partido na Revolução de 1830, como observado anteriormente.

Antes das Revoluções de 1848, a imagem de François Guizot surgiu estampada na imprensa paulista em chave dupla: o grande historiador, referência obrigatória para os estudos modernos, na acepção de Julius Frank ${ }^{20}$; ou o doutrinário da monarquia parlamentar, defensor

\footnotetext{
${ }^{19} \mathrm{O}$ tradutor foi investigado às minúcias por Luís Reis Torgal (1973). Em resenha muito elogiosa a essa pesquisa, José Honório Rodrigues (1974) contribui para completar o perfil de nosso personagem. Teria ele publicado no Rio de Janeiro, além dos títulos acima levantados, uma Memoria sobre a Nobreza no Brasil (1841). Dentre os jornais para os quais colaborou, constam: $O$ Despertador (Rio de Janeiro, ns. 1-27, 1838), dirigido pelo português J. M. da Rocha Cabral, O Exorcista (semanário, 1841), e o Jornal do Commercio. Sobre a obra O Novo Príncipe, escreve: trata-se de "sistematização absolutista e tradicionalista. Nele, inspirado em Maquiavel, o Autor procura destruir a "cabala" liberal, e apresentar um esquema de organização do país em moldes tradicionalistas. Seu subtítulo recorda $O$ Espirito das Leis, de Montesquieu, que ele considerava o responsável pelo sentido revolucionário que destruiu as monarquias absolutas. Nele estão as linhas fundamentais da teoria política de Gama e Castro. Não é uma defesa do miguelismo, mas do pensamento político contrarrevolucionário e tradicionalista português. (RODRIGUES, 1974, p. 42-43).

20 "A aula de Historia e Geographia devia achar-se na vizinhança da Bibliotheca, por motivos tão claros que seria ocioso apontal-os, e esta Bibliotheca mormente pela tendencia do século actual, e pelos enormes desvarios que tem produzido na legislação e administração de muitos païzes a falta de conhecimentos das relações politicas, da
} Jangada | ano 9, nr. 17, jan/jun, 2021 | ISSN 2317-4722 29 |P á g in a 


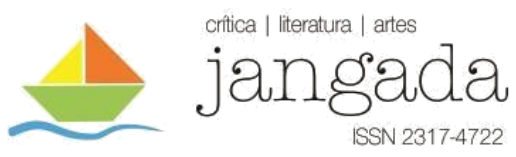

do modelo inglês, muito discutido, aliás, durante a Regência, ou da monarquia constitucional vitoriosa em França, de 1830 a 1848 - período em que a carreira política de nosso personagem atingiu o zênite, na condição de Primeiro Ministro de Luís Filipe. É possível que a Revolução de Fevereiro tenha operado sobre o ex-ministro uma guinada ultraconservadora, o que o fez abandonar uma postura moderada, própria do partido orleanista, para um radicalismo à direita, que não encontrou paralelo nem mesmo na agremiação da rue de Poitiers ${ }^{21}$. A postura inflexível que Guizot adota diante das reivindicações que enfeixaram a Revolução de Fevereiro sinaliza esse fenômeno. Mas a Revolução não teria provocado essa mesma guinada em Alexis de Tocqueville, ou mesmo em Adolphe Thiers? O instinto de sobrevivência, ou mesmo o horror às revoluções, conduziram-nos ao apoio a Luís Napoleão Bonaparte, enquanto François Guizot abandonava a arena política, após a publicação deste libelo e uma candidatura malograda nas eleições legislativas de maio de 1849.

A segunda vaga de recepção das ideias de Guizot, em parte promovida pela ampla difusão de seu libelo político de 1849 , vai ao encontro da política de conciliação de cariz conservador buscada pela classe política brasileira. Como observa Alfredo Bosi, a Primavera dos Povos se coloca como ponto de clivagem de uma polarização política que distingue, claramente, "o liberalismo clássico, proprietista e excludente e, quando lhe é proveitoso, racista e escravista. De outro, o radicalismo democrático, que tem como horizonte precisamente superar as barreiras de classe e de raça que os liberais conservadores ergueram para defender os seus privilégios” (BOSI, 2013, p. 272-273). Não restam dúvidas de que os partidários de Guizot, no Brasil, viam-se menos entusiasmados com os rumos do liberalismo - pelo menos, em relação aos tempos da vitória orleanista (1830) - sobretudo porque a "igualdade" defendida em 1848 colocava em risco a defesa da propriedade. Ora, a defesa do voto censitário era a expressão mais imediata desse pensamento, uma vez que o ato de votar e o direito de ser elegível se vinculavam à propriedade, à posse de bens.

Essas ponderações demarcam uma linha tênue, porém, não sem importância, que distingue o historiador-doutrinário do juste milieu de 1830 e o panfletário antidemocrático de 1848. Parece evidente que a ameaça da república social colocara em relevo a segunda figura, nesses anos conturbados de 1848 e 1849. O medo da revolução atinge em cheio os leitores

posição diplomática, de documentos historicos - devia conter mais obras modernas. Ha revistas em abundancia; pergunte-se por Herder, Heeren, Wardens, Guizot, Thiers \& C. - não existem na livraria" (O Novo Farol Paulistano, Sábado, 31 de dezembro de 1836, p. 2).

${ }^{21} \mathrm{O}$ Partido Orleanista estava agremiado em um comitê nesta rua parisiense.

Jangada| ano 9, nr. 17, jan/jun, 2021 | ISSN 2317-4722 


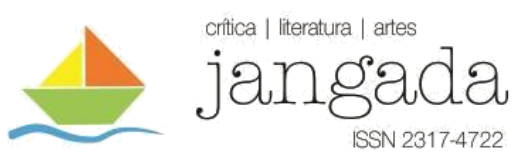

brasileiros, e o prólogo de José Lúcio Correia não deixa dúvidas quanto a essa mudança de perspectiva $^{22}$. Não parece, tampouco, outro o sentido da defesa que faz Justiniano José da Rocha - segundo Parron (2016), o teórico conservador da política da conciliação - quanto ao significado profundo de suas doutrinas para todos os sistemas de governo, como havia assinalado n'O Brasil.

Noutros termos, como reza a longa tradição liberal evocada no início do presente artigo, os pilares da fraternidade e da liberdade foram preservados em nome da ordem constitucional. Nesse sentido, a impossível igualdade se apresenta como a expressão cabal de uma História que teima em se construir à revelia da representação popular. No que toca aos movimentos liberais que eclodiram no Brasil nos anos de 1840, a fatura final foi bem compreendida pelo senador Nabuco de Araújo (1813-1878)23, outra importante testemunha ocular da história: tanto quanto em Minas e em São Paulo, os maiores derrotados de Pernambuco foram os liberais. A derrota da Praieira selou a sorte dos conservadores no poder. Apenas uma nova crise mudaria esse quadro político, mas, dessa vez, era a República, e não mais os concertos do regime monárquico, que entrariam em cena. Enfim, uma outra história.

\section{REFERÊNCIAS BIBLIOGRÁFICAS}

ABREU E LIMA, José Ignacio. Socialismo. Recife, Typographia Universal, 1855.

ADORNO, Sérgio. Os Aprendizes do Poder. O Bacharelismo Liberal na Política Brasileira. 2a. ed. São Paulo, Edusp, 2019. [1 ${ }^{\text {a }}$. ed., 1988]

AGULHON, Maurice. 1848. O Aprendizado da Republica. São Paulo, Paz e Terra, 1991.

AIRES, Vivian Nany. Da Sala de Leitura à Tribuna: Livros e Cultura Jurídica em São Paulo no Século XIX. Tese de Doutorado, São Paulo, Fac. de Filosofia, Letras e Ciências Humanas da Universidade de São Paulo, 2018.

AZEVEDO, Álvares de. Cartas de Alvares de Azevedo. Comentários de Vicente de Azevedo. São Paulo, Academia Paulista de Letras, 1976.

\footnotetext{
${ }^{22}$ Todavia, não estamos a tratar da primeira tradução do autor no Brasil. Consta na Biblioteca Mario de Andrade, na seção de Obras Raras um exemplar de Theoria do governo representativo de M. Guisot [sic]. Extractada de suas obras políticas por ***. Pernambuco [Recife]: Typographia de Santos \& Companhia, 1845. 168 p. O tradutor brasileiro não foi identificado, mas consta que o texto foi extraído da edição de Paris, 1831. Contém, ainda, uma lista de subscriptores para publicação desta obra em 1844. O livro, sem dúvida, merece uma análise mais detida.

${ }^{23} \mathrm{O}$ capítulo que Joaquim Nabuco dedica à participação de seu pai nesse episódio não deixa dúvidas sobre a importância da Praieira no aprendizado da política para os de sua geração (NABUCO, 1936).
} 


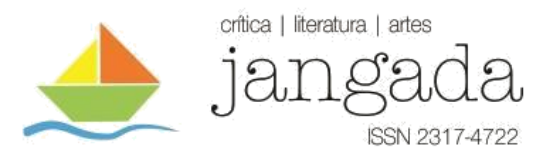

Obras Completas. Organizada e Anotada por Homero Pires. 8ª ed. São Paulo, Companhia Editora Nacional, 1942, 2 t.

BOSI, Alfredo. Entre a Literatura e a História. São Paulo, Editora 34, 2013.

DEAECTO, Marisa Midori. História de Um Livro. A Democracia na França, de François Guizot. Cotia, Ateliê Editorial, 2021.

. O Império dos Livros. Instituições e Práticas de Leituras na São Paulo Oitocentista.

2. ed. São Paulo, Edusp, 2019. [1ª . ed., 2011]

DEAECTO, Marisa Midori; SECCO, Lincoln F. "Seditious Books and Ideas of Revolution in Brazil (1830-1871)". In: VASCONCELOS, Sandra Guardini; SILVA, Ana Claudia Suriani da (orgs.). Books and Periodicals in Brazil (1768-1930). A Transatlantic Perspective. London, Legenda, 2014, p. 52-67.

ESPAGNE, Michel. Les Transferts Culturels Franco-Allemands. Paris, PUF, 1999.

FARIA, Maria Isabel; PERICÃO, Maria da Graça. Dicionário do Livro. Da Escrita ao Livro Eletrônico. São Paulo, Edusp, 2008.

FREYRE, Gilberto. Um Engenheiro Francês no Brasil. Prefácio de Paul Arbousse-Bastide. Rio de Janeiro, José Olympio, 1960, 2 t.

GALLO, Ivone. "O Brasil e o Socialismo do Século XIX: Fourieristas no Saí". In: Franceses no Brasil. Séculos XIX-XX. Org. por Tania Regina de Luca e Laurent Vidal. São Paulo, Ed. Unesp, 2009, p. 147-160.

GODECHOT, Jacques. 'L'Expansion de la Déclaration des Droits de l'Homme de 1789 dans le Monde”. In: Annales Historiques de la Révolution Francaise, n. 232, p.201-213, 1978.

GONÇALVES, Adelaide. "As comunidades utópicas e os primórdios do socialismo no Brasil". In: E-topia: Revista Electrónica de Estudos sobre a Utopia, n. ${ }^{\circ}$ 2, 2004.

GUIZOT, Francois. A Democracia em França. Tradução em portuguez por *** [José da Gama e Castro]. Rio de Janeiro, Livraria d' Agostinho Freitas Guimaraes \& Cia., 1849.

HALLEWELL, Laurence. O Livro no Brasil. Sua História. 2. ed. São Paulo, Edusp, 2012. [1 . ed., 1985]

HOBSBAWM, Eric. Ecos da Marselhesa. São Paulo, Companhia das Letras, 1996.

HOLANDA, Sergio Buarque de. Capítulos de História do Império. São Paulo, Companhia das Letras, 2010.

IGLÉSIAS, Francisco; SOUZA, J. A. Soares de; HOLANDA, Sérgio Buarque de. História Geral da Civilização Brasileira: O Brasil Monárquico, Rio de Janeiro, Bertrand Brasil, 1987, v. 6, tomo II.

MAIOR, Paulo M. Souto. Nos Caminhos do Ferro: Construções e Manufaturas noRecife (1830-1920). Recife, CEPE, 2015. 


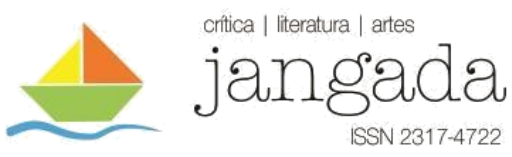

MARSON, Izabel Andrade. Revolução Praieira, Resistencia Liberal a Hegemonia Conservadora em Pernambuco e no Império (1842-1850). São Paulo, Fundação Perseu Abramo, 2009.

MARTINS, Oliveira. Portugal Contemporâneo. Lisboa: Guimarães Editores, 1952.

MOTA, Carlos Guilherme. A Ideia de Revolução no Brasil e Outras Histórias. São Paulo, Globo, 2008. [1 ${ }^{\text {a }}$. ed. 1970].

NABUCO, Joaquim. Um Estadista do Império. Sua Vida, Suas Opiniões, Sua Época. São Paulo/Rio de Janeiro, CEA/Civilização Brasileira, 1936, 2 vols. [1. ed., 1897].

OEHLER, Dolf. O Velho Mundo Desce aos Infernos. Autoanalise da Modernidade Após os Traumas de Junho de 1848 em Paris. São Paulo, Companhia das Letras, 1999.

"Officio da Camara ao Exmo. Vice-Presidente desta Província, e seu Conselho", São Paulo, 8 de outubro de 1830', Registro Geral da Câmara, vol. XX, São Paulo, 1832.

PAIVA, Tancredo de Barros. Acchêgas a um Diccionario de Pseudonymos. Iniciaes, Abreviaturas e Obras Anonymas de Auctores Brasileiros Sobre o Brasil ou no Mesmo Impressas. Rio de Janeiro, J. Leite e Cia., 1929.

PRADO JR., Caio. Evolução Política do Brasil e Outros Estudos. 3. ed. São Paulo, Brasiliense, 1961. [1 ${ }^{\mathrm{a}}$. ed., 1933]

PORTO, Walter da Costa. O Voto no Brasil. Da Colônia à Sexta República, 2. ed. rev., Rio de Janeiro, Topbooks, 2002.

QUINTAS, Amaro. “O Espirito 'Quarante-Huitard' e a Revolução Praieira”. In: Revista de História, vol. 19, n. 40, p. 303-324, 1959.

QUINTAS, Amaro. O Sentido Social da Revolução Praieira. Rio de Janeiro, Civilização Brasileira, 1967.

ROCHA, Justiniano José da. Ação; Reação; Transação. Duas Palavras Acerca da Atualidade Política do Brasil (1855), Estudo Introdutório, Notas e Estabelecimento do Texto por Tâmis Parron, São Paulo, Edusp, 2016.

RODRIGUES, José Honório, “Resenha”, Revista de História, v. 48, n. 98, 1974.

SECCO, Lincoln. História da União Soviética. São Paulo, Ed. Maria Antônia, 2020.

SILVA, Inocêncio Francisco da. Dicionário Bibliográfico Português, tomo IV, Lisboa, Imprensa Nacional, 1973.

THEIS, Laurent. Francois Guizot. Paris, Fayard, 2008. 